\title{
PROTOTIPE SISTEM OTOMATIS LAMPU ULTRAVIOLET-B PADA KANDANG BURUNG DENGAN SENSOR SUHU BERBASIS MIKROKONTROLER ARDUINO
}

\section{Prototype Automatic System Ultraviolet-B Light in Bird Cage With Arduino Microcontroller Based Temperature Sensor}

\author{
Vina Septiana Windyasari, vswindyasari@ unis.ac.id $^{1)}$ M.Andika Candra ${ }^{2)}$ \\ ${ }^{1,2)}$ Teknik Informatika, Fakultas Teknik, Universitas Islam Syekh-Yusuf Tangerang
}

\begin{abstract}
Today's technological developments are not only limited to entrepreneurs, students, communities, but also to farmers. Phenomena that often occur especially in poultry farmers include problems with the temperature in closed rooms that certainly change so as to affect the growth and survival of birds, and weather that is too cold or hot can affect comfort in birds, so as to help and enrich the development of technology-based microcontrolle, in this design using microcontrolroller Arduino Uno, in this study designed a prototype that is the design of automatic setting of Ultraviolet-B lamps with temperature sensor DHT11 that can be applied to closed aviary especially for chirping birds, and such as the use of heating lamps in closed aviary is using Ultraviolet-B lamps as a substitute for sunlight that is beneficial for living needs as well as the growth process of birdsong to get a fairly warm irradiation, helping bird farmers who can be adjusted or programmed to the required temperature, in this design using the model prototype system development method, the trial was carried out by controlling incoming light so that it affects the temperature of the drum that produces the detection of DHT11 temperature sensor automatically ultraviolet-B lamp can light with the provisions of temperature $<29.50^{\circ} \mathrm{C}$ and lights off at a temperature of $\geq 32^{\circ} \mathrm{C}$ that can be displayed on the $L C D$ layer, so it can help to control the temperature and lights automatically.
\end{abstract}

Keywords: Microcontrolle, Arduino Uno, Ultraviolet-B Lamp, DHT11 Temperature Sensor

\begin{abstract}
ABSTRAK
Perkembangan teknologi sekarang ini tidak hanya terbatas untuk para pengusaha, pelajar, komunitas, namun juga merambah untuk para peternak. Fenomena yang sering terjadi khususnya pada peternak unggas burung diantaranya adalah permasalahan terhadap suhu pada ruangan tertutup yang pastinya berubah-ubah sehingga mempengaruhi tumbuh kembang dan kelangsungan hidup unggas burung, dan cuaca yang terlalu dingin atau panas dapat mempengaruhi kenyamanan pada unggas burung, maka untuk membantu dan memperkaya perkembangan teknologi berbasis mikrokontroller, pada rancangan ini menggunakan jenis mikrokontroller Arduino Uno, pada penelitian ini merancang sebuah prototype yaitu rancangan pengaturan otomatis lampu Ultraviolet-B dengan sensor suhu DHT11 yang dapat diterapkan pada kandang burung tertutup khususnya untuk burung kicau, dan seperti penggunaan lampu penghangat pada kandang burung tertutup ini menggunakan lampu Ultraviolet-B sebagai pengganti sinar matahari yang bermanfaat untuk kebutuhan hidup juga proses pertumbuhan unggas burung untuk mendapatkan penyinaran yang cukup hangat, membantu peternak unggas burung yang dapat disesuaikan atau terprogram dengan suhu yang dibutuhkan, pada rancangan ini menggunakan metode pengembangan sistem prototype model, uji coba dilakukan dengan pengkontrolan cahaya yang masuk sehingga mempengaruhi suhu kendang yang menghasilkan pendeteksian sensor suhu DHT11 secara otomatis lampu ultraviolet-B dapat menyala dengan ketentuan suhu $<29.50^{\circ} \mathrm{C}$ dan lampu mati pada suhu $\geq 32^{\circ} \mathrm{C}$
\end{abstract}


yang dapat ditampilkan pada layer LCD, sehingga dapat membantu untuk pengkontrolan suhu dan lampu secara otomatis.

Kata Kunci: Mikrokontroller, Arduino Uno, Lampu ultraviolet-B, Sensor Suhu DHT11

\section{PENDAHULUAN}

Ada saatnya kurun waktu mendorong manusia untuk terus berfikir kreatif, tidak hanya menggali penemuan-penemuan baru, tapi juga memaksimalkan kinerja teknologi yang ada untuk meringankan kerja manusia dan juga upaya untuk menghemat energi dalam kehidupan sehari-hari seperti pengendalian lampu rumah atau perangkat elektronik lainnya. Penggunaan teknologi secara efektif juga masih menjadi isu yang hangat di perbincangkan. Dikutip secara umum, pengguaan teknologi secara efektif dapat meminimalisir waktu agar lebih cepat dapat dilakukan dengan dua cara, yaitu dengan peningkatan efisiensi teknologi yang digunakan, atau dengan merubah perilaku penggunanya (Herlan dan Lintang, 2012). [1]

Pada saat di lakukannya observasi pada peternak burung di kecamatan Pasar Kemis Tangerang, para peternak burung masih menyalakan lampu mengunakan sistem manual yaitu dengan menuju ke saklar lampu yang terhubung ke aliran listrik utama pada rumah untuk menyalakan lampu penghangat yang berada dalam kandang ternak burung kicau. Hal tersebut yang menarik untuk melakukannya penelitian dalam penggunaan lampu penghangat pada kandang ternak burung kicau tersebut, yang terdapat kurang efisien dalam penggunaan lampu penghangat yang terdapat pada kandang burung kicau. Penelitian menggunakan lampu UltravioletB sebagai pengganti sinar matahari yang bermanfaat untuk kebutuh hidup pertumbuhan burung. Sehingga para pemelihara burung tidak perlu khawatir dengan kebutuhan sinar ultraviolet, dengan menggunakan sistem kontrol suhu untuk menyalakan lampu Ultraviolet-B secara otomatis ini. Pada penelitian-penelitian sebelumnya dilakukan oleh Herlan dan Lintang Dwi Febridiani (2018) menggunakan sistem berbasis mikrokontroler AT89C52 dengan memaksimalkan cahaya dari luar ruangan serta pengaturan kondisi penyalaan lampu berdasarkan keberadaan orang di dalam ruanga[1], dan Haris dan Ary (2017), membahas mengenai bagaimana cara merancang sistem lampu otomasis menggunakan sensor suara dengan kesimpulan sistem akan berfungsi ketika sensor suara FC-04 mendapat input suara (kode bunyi) berupa tepukan yang bernilai 1 kemudian diakumulasikan pada arduino dengan nilai diatas 400 millis sesuai program yang diupload untuk dijadikan keluaran 5 volt untuk menyalakan/memadamkan lampu. Untuk menyalakan lampu dengan jarak jangkauan tertentu ada beberapa hal yang mempengaruhi seperti, pengaturan tingkat sensitifitas sensor suara dan tingkat kebisingan sekitar area ruangan[3]. Penelitian Ihsanto dan Muhamad Dawud (2016), penelitian untuk memastikan perlu tidaknya lampu dihidupkan, diperlukan sensor cahaya, dalam hal ini LDR, Light Dependent Resistor. Sedangkan informasi yang terkait dengan keadaan sistem penerangan dikirimkan via SMS. Sistem otomatis seperti ini dikendalikan menggunakan mikrokontroler. Setelah dilakukan beberapa kali pengujian, sistem ini terbukti efektif mendeteksi cahaya, dan otomatis mengaktifkan lampu jika keadaan cukup gelap. Terkait dengan perawatan, sistem ini terbukti dapat mengirimkan SMS notifikasi sesuai dengan keadaan saat itu [2]. Maka untuk membantu para peternak burung kicau pada penelitian ini menggunakan prototype sistem otomatis lampu ultraviolet-B berbasis microcontroller arduino, menggunakan prototype model.

Berdasarkan latar belakang tersebut maka masalah ini dapat diidentifikasi sebagai berikut :

1. Apakah dapat merancang sistem otomatis lampu ultraviolet-B pada 
kendang burung dengan sensor suhu berbasis mikrokontroller arduino

2. Bagaimana merancang program lampu ultraviolet-B secara otomatis pada kendang burung dengan sensor suhu berbasis mikrokontroller arduino

3. Bagaimana cara kerja mikrokontroller arduino pada sensor DHT11 untuk sistem lampu otomatis

Tujuan dan Manfaat dari penelitian ini adalah

1. Dapat mempernudah pihak peternak burung kicau untuk mengidupkan atau mematikan lampu apabila suhu naik atau turun diruang lingkup kandang burung kicau.

2. Dapat menjaga kelembapan suhu pada kandang burung kicau yang dapat mempengaruhi kualitas tumbuh kembang burung kicau.

3. Sebagai acuan atau data yang mendukung penelitian lain di masa yang akan datang khususnya menggunakan mikrokontroler Arduino Uno.

4. Mengembangkan wawasan keilmuan dan dapat bermanfaat dalam bidang teknologi.

\section{METODE PENELITIAN}

Dikutip dari jurnal prototyping merupakan metode pengembangan perangat lunak, yang berupa model fisik kerja sistem dan berfungsi sebagai versi awal dari sistem. Dengan metode prototyping ini akan dihasilkan prototype sistem sebagai perantara pengembang dan pengguna agar dapat berinteraksi dalam proses kegiatan pengembangan sistem informasi. Agar proses pembuatan prototype ini berhasil dengan baik adalah dengan mendefinisikan aturan-aturan pada tahap awal, yaitu pengembang dan penguna harus satu pemahaman bahwa prototype dibangun untuk mendefinisikan kebutuhan awal. Prototype akan dihilangkan atau ditambahkan pada bagiannya sehingga sesuai dengan perencanaan dan analisis yang dilakukan oleh pengembang sampai dengan ujicoba dilakukan secara simultan seiiring dengan proses pengembangan. Ada empat metodologi prototyping yang paling utama yaitu :

1. Illustrative, menghasilkan contoh laporan dan tampilan layar.

2. Simulated, mensimulasikan beberapa alur kerja sistem tetapi tidak menggunakan data real.

3. Functional, mensimulasikan beberapa alaur sistem yang sebenarnya dan menggunakan data real.

4. Evolutionary, menghasilkan model yang menjadi bagian dari operasional sistem. [4]

Menurut Ogedebe (2012), prototyping dimulai dengan pengumpulan kebutuhan, melibatkan pengembang dan pengguna sistem untuk menentukan tujuan, fungsi dan kebutuhan operasional sistem. Langkah-langkah dalam prototyping adalah sebagai berikut :

1. Pengumpulan Kebutuhan.

2. Proses desain yang cepat.

3. Membangun prototipe.

4. Evaluasi dan perbaikan.

Mengumpulkan kebutuhan melibatkan pertemuan antara pengembang dan pelanggan untuk menentukan keseluruhan tujuan dibuatnya perangkat lunak; mengidentifikasi kebutuhan berupa garis besar kebutuhan dasar dari sistem yang akan dibuat. Desain berfokus pada representasi dari aspek perangkat lunak dari sudut pengguna; ini mencakup input, proses dan format output. Desain cepat mengarah ke pembangunan prototipe, prototipe dievaluasi oleh pengguna dan bagian analis desain dan digunakan untuk menyesuaikan kebutuhan perangkat lunak yang akan dikembangkan. prototype diatur untuk memenuhi kebutuhan pengguna, dan pada saat itu pula pengembang memahami secara lebih jelas dan detil apa yang perlu dilakukannya. Setelah keempat langkah prototyping dijalankan, maka langkah selanjutnya adalah pembuatan atau perancangan produk yang sesungguhnya. [4]

Dalam metode perancangan ini yang digunakan adalah metode perancangan 
prototipe melalui tahap pembuatan flowchart yang didesain dengan cara mengikuti kerja sistem, bagaimana sistem itu dirancang dan alat apa saja yang dibutuhkan. [5]. Dengan metode pengembangan sistem berupa prototipe model, peraga prototype dapat dilihat pada Gambar 1

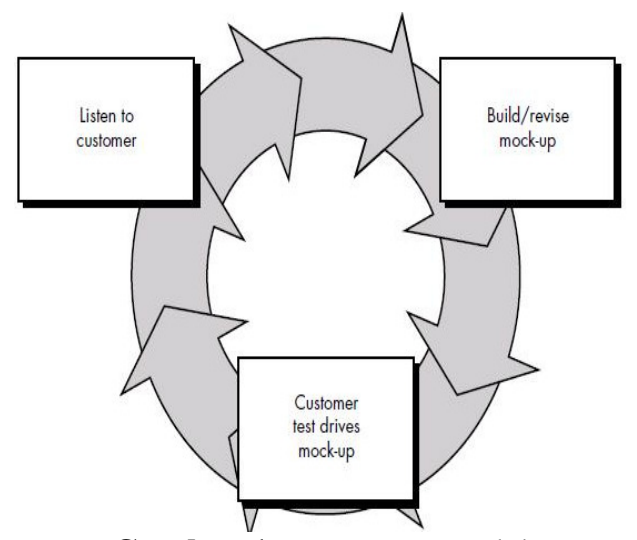

Gambar 1. Prototype Model

Pada pembuatan menggunakan alat antara lain: aplikasi Arduino Integrated Development Environment (IDE), mikrokontroller Arduino Uno, relay, resistor, sensor suhu DHT11, dan lampu Ultraviolet.

\section{HASIL DAN PEMBAHASAN}

Analisa sistem adalah penguraian dari suatu sistem yang utuh ke dalam bagianbagian komponennya untuk mengidentifikasi dan mengevaluasi permasslahan yang akan diangkat. Bagian analisis ini terdidri dari yang sedang berjalan, analisis kelemahan sistem, tujuan perancangan sistem, dan analisis kebutuhan sistem.

Analisa sistem berjalan dapat dilihat pada Gambar 2 diatas, yang penjelasan sebagai berikut :

1. Peternak burung menuju ke kandang

2. Peternak burung menyalakan saklar lampu, agar lampu kandang menyala.
3. Ada pilihan, jika lampu tidak menyala maka peternak mengecek sambungan saklar lampu pada aliran listrik.

4. Jika saklar lampu tidak terjadi kendala maka lampu menyala

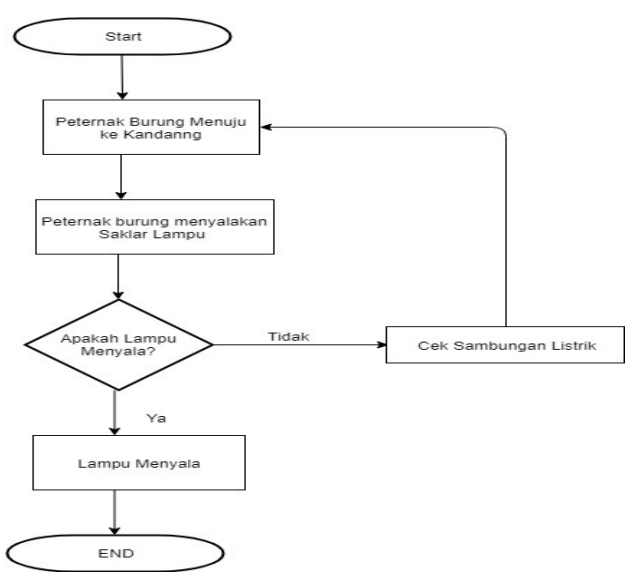

Gambar 2. Diagram Sistem yang Berjalan

Adapun blok diagram mengacu pada Gambar 3 diantaranya :

1. Terdapat 2 (dua) simbol terminal yang berperan sebagai "Mulai" dan "Selesai".

2. Terdapat 4 (empat) simbol proses, yang menyatakan lampu otomatis akan menyala atau tidak menyala.

3. Terdapat 1 (satu) decision, menyatakan YA dan TIDAK jika YA maka akan melanjutkan pada proses selanjutnya, dan jika TIDAK melihat kembali suhu apakah sudah menunjukan pada suhu yang sudah ditentukan.

Berdasarkan analisis sistem yang berjalan tersebut diatas, maka untuk perbaikan sistem dari yang sebelumnya, seperti yang diperagakan pada Gambar 3.

Untuk memperoleh kinerja sistem yang baik, langkah pertama melakukan pengujian terhadap akurasi sensor DHT11. Hasil pengujian nilai suhu yang terukur oleh sensor DHT-11 diperlihatkan pada Tabel 1. Berdasarkan Tabel 1, nilai akurasi sensor DHT-11 sekitar 97,8 \% 
sehingga dapat digunakan untuk mengukur suhu dengan sangat baik.

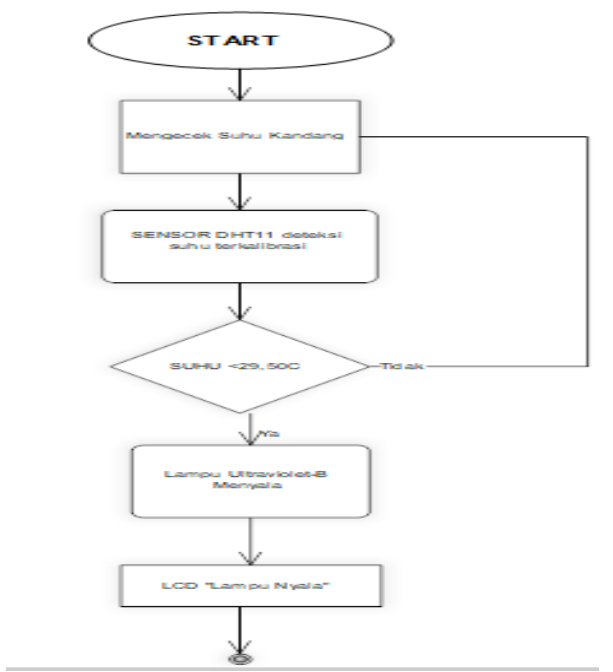

Gambar 3. Diagram Sistem yang dibuat

Tabel 1. Pengujian sensor DHT11

\begin{tabular}{cll}
\hline $\begin{array}{c}\text { Suhu } \\
\text { sebenarny } \\
\text { a }\left({ }^{\circ} \mathrm{C}\right)\end{array}$ & $\begin{array}{l}\text { Hasil } \\
\text { Pengukura } \\
\text { n Sensor } \\
\text { DHT- } 11 \\
\left({ }^{\circ} \mathrm{C}\right)\end{array}$ & $\begin{array}{l}\text { Akuras } \\
\mathrm{i}(\%)\end{array}$ \\
\hline 22 & 22 & 10 \\
24 & 23 & 0 \\
26 & 26 & 96 \\
& & 0 \\
28 & 29 & 96 \\
30 & 29 & 97 \\
32 & 31 & 97 \\
\hline
\end{tabular}

Diterangkan bahwa sensor suhu DHT11 akan membaca suhu pada kandang burung kicau. Ketika suhu menunjukan $<29.50^{\circ} \mathrm{C}$ jika iya maka lampu ultraviolet-B akan hidup otomatis, dan jika sensor suhu mendeteksi suhu dengan keterangan $\geq 32^{\circ} \mathrm{C}$ jika iya maka lampu UVB akan mati dan jika tidak maka option yang di cantumkan harus mengecek pengukuran kalibrasi suhu pada program Mikrocontroller arduino merupakan microcontroller yang dikembangkan oleh Arduinno sehingga mudah digunakan. [6] dapat dilihat pada gambar 4.

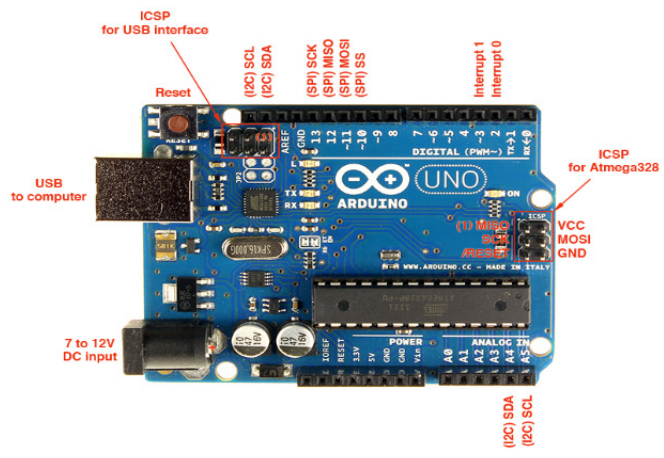

Gambar 4. Mikrokontroller Arduino Uno

Pada sisi implementasi perangkat lunak, maka perlu di-upload script yang mendukung untuk keperluan pembacaan suhu dan kebutuhan dalam menjalankan perangkat yang terhubung dengan mikrokontroller Arduino Uno ini, seperti terlihat pada Gambar 5. Implementasi pada sisi perangkat lunak akan banyak mengakses pada COM Port komputer yang digunakan integrasinya dengan mikrokontroller Arduino Uno, sehingga dapat terhubung baik antara hardware dengan perangkat lunak dalam program yang ditanam pada Arduino uno tersebut sesuai dengan kebutuhannya, yaitu pendeteksian suhu, dan menyalakan lampu.

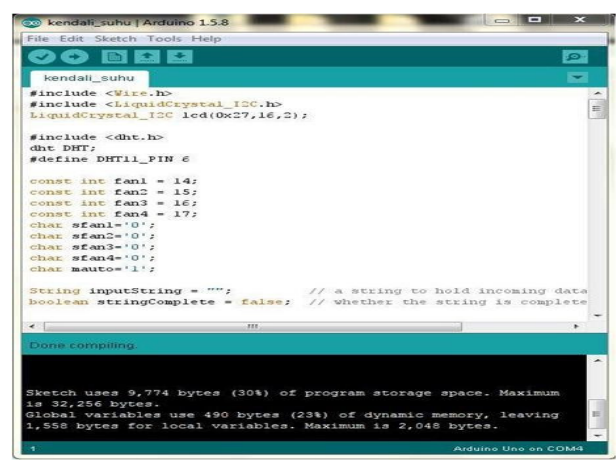

Gambar 5. Script Arduino Uno

Pengoperasian Program dilakukan dengan langkah-langkah sebagai berikut:

1. Pertama-tama yang dilakukan adalah buka software Arduino IDE lalu pergi ke Sketch -> Include Library -> 
Manage Library. Disini adalah tempat mengatur library yang ingin diterapkan, maka ditahap ini adalah proses instalasi daripada library yang diperlukan.

2. Ketikkan DHT pada kolom Search, pilih yang by Adafruit lalu lakukan proses instalasi.

3. Lalu ketikkan Adafruit Unified Sensor dan lakukan hal yang sama yaitu proses instalasi.

4. Jika semua library sudah terinstal, lakukan restart pada Arduino IDE. Library sangat diperlukan karena disini letak daripada berhasilnya proses pemrograman. Setiap komponen mikrokontroler mempunyai librarynya masing-masing.

5. Buat project baru/new project, ini adalah platform untuk memulai suatu pemrograman.

6. Setelah projek pemrograman sudah selesai, kemudian upload pemrograman, tunggu uploading sampai selesai, jika sudah selesai lihat pada Serial Monitor untuk mengetahui IP Address yang didapatkan. Ketikkan IP Address pada browser, lalu tekan enter.

7. Maka data suhu dan kelembapan akan ditampilkan pada layar monitor LCD sehingga mudah dimengerti oleh user. Tampilan dibuat sederhana agar lebih ringan dan mudah proses pengambilan datanya, mengurangi terjadinya lagging atau kelambapan sewaktu jaringan tidak stabil.

Setelah melakukan berbagai tahapan perancangan dan pemasangan komponen, langkah selanjutnya adalah melakukan serangkaian uji coba pada masing-masing blok rangkaian yang bertujuan untuk mendapatkan hasil yang sesuai dengan harapan. Tujuan dari pembahasan hasil uji coba tersebut antara lain agar setiap rangkaian-rangkaian komponen yang dipakai lebih mudah untuk dipahami. Adapun penjelasan dari hasil pengujian sebagai berikut :
1. Sensor suhu DHT11 mendeteksi suhu $<29.50^{\circ} \mathrm{C}$, maka lampu ultraviolet-B akan menyala otomatis dan memberikan notifikasi Lampu Nyala pada LCD. Diperagakan pada Gambar 6

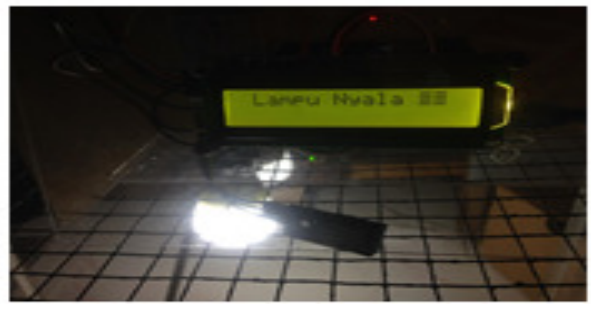

Gambar 6. Lampu ultraviolet-B menyala

2. Sensor suhu DHT11 mendeteksi suhu $\geq 32.0^{\circ} \mathrm{C}$, maka lampu ultraviolet-B akan mati otomatis dan memberikan notifikasi Lampu Mati pada LCD Seperrti yang diperagakan pada Gambar 6

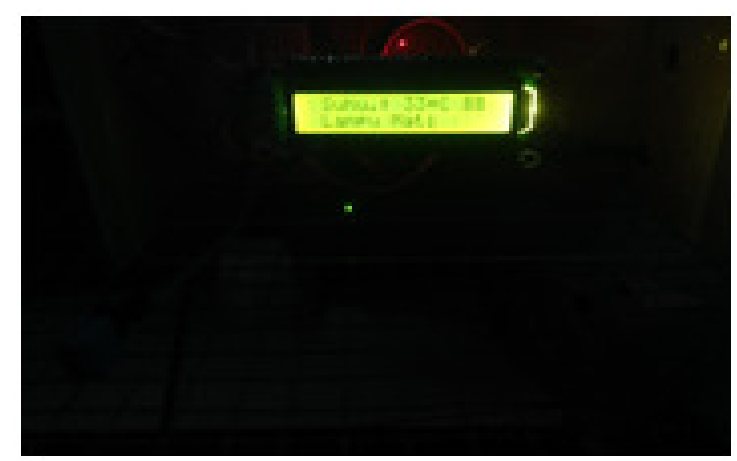

Gambar 6. Lampu ultraviolet-B mati

Perbedaan prosedur antara sistem yang berjalan dan sistem yang diusulkan dapat dilihat pada Tabel 2. Pada sistem yang berjalan belum menggunakan lampu ultraviolet-B masih menggunakan sistem manual maka pada sistem yang baru dibuat proses menyala dan mematikan lampu ultraviolet-B sudah menggunakan sensor suhu DHT11.

Pada sistem yang berjalan masih kurangnya ketepatan waktu untuk menyala dan mematikan lampu sehingga dapat memperngaruhi kelembapan suhu pada kandang burung. Pada sistem baru yang 
dibuat dengan sensor suhu yang sudah ditentukan batasan suhu $<29.50^{\circ} \mathrm{C}$ lampu menyala dan suhu $\geq 32.0^{\circ}$ lampu akan padam dengan suhu yang telah terkalibrasi dengan alat mikrokontroller Arduino uno.

Tabel 2. Perbedaan Prosedur Antara Sistem Yang Berjalan dan Sistem Yang Diusulkan

\begin{tabular}{|c|c|c|}
\hline No & Sistem yang berjalan & Sistem yang dibuat \\
\hline 1 & $\begin{array}{lr}\text { Pada sistem } & \text { yang } \\
\text { berjalan } & \text { belum } \\
\text { menggunakan } & \text { lampu } \\
\text { ultraviolet-B } & \text { masih } \\
\text { menggunakan } & \text { sistem } \\
\text { manual } & \\
\end{array}$ & $\begin{array}{lr}\text { Pada sistem yang dibuat } \\
\text { proses menyala } \\
\text { mematikan } & \text { dampu } \\
\text { ultraviolet-B } & \text { sudah } \\
\text { menggunakan sensor suhu } \\
\text { DHT11 }\end{array}$ \\
\hline 2 & $\begin{array}{l}\text { Pada sistem yang } \\
\text { berjalan masih } \\
\text { kurangnya ketepatan } \\
\text { waktu untuk menyala } \\
\text { dan mematikan lampu } \\
\text { sehingga dapat } \\
\text { memperngaruhi } \\
\text { kelembapan suhu pada } \\
\text { kandang burung }\end{array}$ & $\begin{array}{l}\text { Pada sistem yang dibuat } \\
\text { dengan sensor suhu yang } \\
\text { sudah ditentukan batasan } \\
\text { suhu }<29.50^{\circ} \mathrm{C} \text { lampu } \\
\text { menyala dan suhu } \geq 32.0^{\circ} \mathrm{C} \\
\text { yang terkalibrasi dengan } \\
\text { alat mikrokontroller } \\
\text { Arduino uno }\end{array}$ \\
\hline
\end{tabular}

Hasilnya dapat dipastikan pada tingkat suhu $<29.50^{\circ} \mathrm{C}$ maka secara otomatis lampu ultraviolet-B pada kandang burung menyala, dan jika pada kandang burung suhu telah mencapai $\geq 32.0^{\circ} \mathrm{C}$ maka lampu ultraviolet-B akan mati atau padam seperti yang mengacu pada gambar 5 dan 6

\section{SIMPULAN}

Berdasarkan hasil penelitian yang telah dilakukan, maka memperoleh sebuah kesimpulan dari permasalahan, yaitu ;

1. Dapat dirancangnya sistem kontrol otomatis pada lampu ultraviolet-B dengan pengaturan kalibrasi sensor suhu DHT11 berbasis mikrokontroller arduino, yang menjawab rumusan masalah pertama bahwa dapat dibuatnya rancangan sistem otomatis berbasis arduino.

2. Menjawab rumusan masalah kedua perancangan dilakukan dengan menggunakan metode pengembangan sistem prototype model, dan alat mikrokontroller Arduino Uno yang mendeteksi untuk suhu dengan jenis sensor DHT11.
3. Pada sensor suhu DHT11 bekerja dengan cara membaca suhu yang terkalibrasi dengan mikrokontroller arduino pada kandang burung dengan ketentuan suhu $<29.50^{\circ} \mathrm{C}$ maka lampu ultraviolet-B akan menyala dan suhu dalam kandang naik dengan keterangan $\geq 32^{\circ} \mathrm{C}$ maka lampu Ultraviolet-B akan otomatis padam yang akan di tampilkan pada layer LCD, menjawab untuk permasalahan ketiga.

\section{DAFTAR PUSTAKA}

[1] Herlan dan Lintang Dwi Febridiani. (2012). Perancangan Pengatur Lampu Otomatis untuk Penghemat Energi Berbasis Mikrokontroler AT89C52, 3(7), 47-62.

[2] Eko Ihsanto dan Muhamad Dawud. (2016). Sistem Monitoring Lampu Penerangan Jalan Umum Menggunakan Mikrontroler Arduino dan Sensor LDR Dengan Notifikasi SMS. 6(4), 2-18.

[3] Muh. Yusrifar Haris dan Ary Abdi Putra (2017). Perancang Sistem Lampu Berbasis Mikrokontroler Arduino R3 Dengan Sensor Suara, 1(2), 1-17.

[4] Purnomo, Dwi (2017). Model Prototyping Pada Pengembangan Sistem Informasi. Jurnal Informatika Merdeka Pasuruan, 2(2), 54-61

[5] Prayudita, Raheza (2018). Rekayasa Perangkat Lunak, metode prototype. [Available from http://www.materikuliahifunpas.com/2018/07/metodeprototype.html]

[6] Mikrokontroler. Diakses pada Desember 23, 2020, dari https://ilearning.me/sample-page162/arduino/pengertian-arduinouno/ 